\title{
Investigation the requirements of supply and distribution emergency logistics management and categorization its sub-criteria using AHP: a case study
}

\author{
Sadegh Feizollahi $^{a^{*}}$, Alireza Shirmohammadi ${ }^{\mathrm{b}}$ and Zahra Safari Kahreh ${ }^{\mathrm{c}}$
}

${ }^{a}$ Department of Management, Islamic Azad University (IAU), Mehran, Iran

${ }^{b}$ Department of Industrial Management, Payame Noor University, Tehran, Iran

${ }^{c} M S c$ in Managerial Finance and Lecture of Payame Noor University, Ilam, Iran

\section{A R T I C LEI NF O A B T R A T}

\section{Article history:}

Received May 14, 2012

Received in Revised form

June, 26, 2012

Accepted 2 August 2012

Available online

August 92012

\section{Keywords:}

Management preparation and

distribution

Crisis management

Logistic emergency

Analytic-Hierarchy-process

\begin{abstract}
The management of procurement and distribution is one of the most important branches of the crisis management and events that, has great importance in the field of management. In this paper, we perform an empirical study to investigate important factors on emergency logistic emergency preparation distribution management among people who worked for governorship, hygiene and treatment, Red Crescent, electricity, water and sewage and transportation of central province of Ilam in west part of Iran. The survey distributed a questionnaire among some people and examined six hypotheses. The results of our survey indicate that employees who worked for these organizations maintained high levels of skills; they were able to access what they needed in their organization. In addition, the survey indicates that the access to the necessary information in their organizations; they are able to take care of their documentations. They could also execute their jobs based on good schedules and accomplished their tasks, properly. They survey also performed a multi-criteria decision making approach using AHP to prioritize important activities to improve logistic operations. The results indicate that having a good database is number one priority with relative weight of 0.51 , followed by appropriate operating planning with relative weight of 0.295 . Supply control came on the third position with relative weight of 0.134 and finally task assignment came as the last priority with relative weight of 0.061 .
\end{abstract}

\section{Introduction}

During the past few years, there have been different techniques to tackle emergency logistics problems since its first implementation in maritime disaster situations in the 1970s. Caunhye et al. (2012) performed a comprehensive review on different techniques utilized in emergency logistics. They explained that disaster operations could be performed before or after disaster incidents happen. Quick-notice evacuation, facility layout, and stock pre-positioning could be used as the main pre-

* Corresponding author.

E-mail addresses: sadegh_feizollahi@yahoo.com (S. Feizollahi) 
disaster operations, while relief distribution and casualty transportation are categorized as postdisaster operations.

Chang et al. (2007) developed a decision-making tool, which could be used by government agencies in planning for flood emergency logistics. They formulated the flood emergency logistics problem with uncertainty as two stochastic programming models, which allows for the determination of a rescue resource distribution system for urban flood disasters. They also used a real-world case study for flood emergency logistics to highlight the effects of the proposed model as well as the efficacy of the proposed solution strategy.

Yuan and Wang (2009) explained that path selection is one of the main problems in emergency logistics management and presented two mathematical techniques for path selection in emergency logistics management by considering more actual factors in time of disaster. They also used simulation technique and their results indicated that the effectiveness and feasibility of the models and algorithms were promising.

Hu (2011) proposed an integer linear programming model to build the path selection for container supply chain in the context of emergency relief. His simulation study indicated that the method maintained promising effects. The study was valuable for designing the emergency logistics management system with optimal path selection and flow design of container supply chain in disaster environments. There are also growing interests among practitioners for adapting methods for decision making processes, which rely on both financial and non-financial figures in logistic management systems (Kaplan \& Norton, 1992; Kaplan, \& Norton, 1996).

Sheu (2010) presented a dynamic relief-demand management model for emergency logistics operations under imperfect information conditions in large-scale natural disasters. The proposed methodology includes three steps: (1) data fusion to forecast relief demand in multiple areas, (2) fuzzy clustering to classify affected area into groups, and (3) multi-criteria decision making to rank the order of priority of groups. They reported that the overall forecast errors were lower than $10 \%$ inferring the proposed method's capability of dynamic relief-demand forecasting and allocation with imperfect information to facilitate emergency logistics operations.

Gong et al. (2012) constructed the operation model and its evaluation index system for emergency logistics system. They explained the imperfection of subjective determining index weight method in traditional evaluation and determined the index weight coefficients by information entropy method of combining subjective judgment with objective evaluation. They also used the fuzzy clustering and information entropy to determine the weights into emergency logistics system reliability evaluation.

Zhang et al. (2012) proposed a new node-weighted bottleneck Steiner tree based multi-objective location optimization technique for the emergency logistics systems and a cellular stochastic diffusion search based intelligent algorithm was introduced to solve the proposed model. They also used numerical experiments to show that the proposed approach was effective and efficient for solving the location problem of emergency logistics systems.

\section{Research hypothesis}

The proposed research study of this paper considers the following hypotheses.

1. The Involved organizations are familiar with their own duties in preparation and distribution management, perfectly

2. The organizations have identified the necessary needs, which are relevant with their own organization through events.

3. The organizations have integrated necessary needs for events based on appropriate information. 
4. Organizations have suitable facilities to protect their documentations.

5. The organizations take the necessary actions based on an appropriate time schedule.

6. The members of the organizations have good cooperation in work.

\subsection{Research method}

The proposed study of this research has been implemented among people who worked for different units in city of Ilam, Iran. The population of our survey includes 110 people who worked for governor ship, hygiene and treatment, red crescent, electricity, water and sewage and transportation of central province. Therefore, we could use the following formula to calculate the minimum number of sample size,

$n=\frac{N \times z_{\alpha / 2}^{2} \times p \times q}{\varepsilon^{2} \times(N-1)+z_{\alpha / 2}^{2} \times p \times q}$,

where $N$ is the population size, $p=1-q$ represents the yes/no categories, $z_{\alpha / 2}$ is CDF of normal distribution and finally $\varepsilon$ is the error term. Since we have $p=0.5, z_{\alpha / 2}=1.96, \varepsilon=0.14$ and $N=110$, the number of sample size is calculated as $n=35$. We have designed a questionnaire consists of 27 questions in terms of Likert scale (5 scales).

\subsection{Data analysis}

Generally, in order to evaluate and analyze the data in this research we use non-parametric tests to analyze our hypotheses. The proposed study of this paper uses Chi-Square test to see whether there is any difference between expected and observed data. Let $\mathrm{F}_{\mathrm{ei}}$ and $\mathrm{F}_{\mathrm{oi}}$ be the frequencies of expected and observed for the sample of the proposed study. Therefore, Chi-square statistics can be computed as follows,

$\chi^{2}=\frac{\sum_{i=1}^{n}\left(F_{o i}-F_{e i}\right)^{2}}{F_{e i}}$.

In our survey, the level of significance is five percent and Chi-Square figures are calculated with four degrees of freedom, which yields $\chi_{4,0.05}^{2}=9.49$. Obviously, if the calculated Chi-Square for any hypothesis of this study is more than 9.49 , the null hypothesis is rejected.

\section{The results}

In this section, we present details of our survey on six hypotheses of this survey as well as the results of our survey on ranking different criteria influencing logistic emergency preparation distribution management.

\subsection{Testing six hypotheses}

The first step in our survey is to examine all six hypotheses of the survey.

\subsubsection{First hypothesis: Familiarity of members of organizations on their duties}

The first hypothesis is associated with the level of their familiarity on members of the organizations. The Chi-Square is calculated as $47.214>\chi_{4,0.05}^{2}=9.49$. Therefore, we can conclude that the null 
hypothesis is rejected and there is enough evidence to believe that employees who work for these organizations maintain high levels of skills.

\subsubsection{Second hypothesis: Capability of members of organizations to access their needs}

The second hypothesis surveys whether members of studied organizations are able to access their requirements. The Chi-Square is calculated as $49.428>\chi_{4,0.05}^{2}=9.49$. Therefore, we can conclude that the null hypothesis is rejected and there is enough evidence to believe that employees who work for these organizations are able to access what they need in their organization.

\subsubsection{Third hypothesis: Capability of members of organizations to reach necessary information}

The second hypothesis surveys whether members of studied organizations have the access to necessary information or not. The Chi-Square is calculated as $70.171>\chi_{4,0.05}^{2}=9.49$. Therefore, we can conclude that the null hypothesis is rejected and there is enough evidence to believe that employees who work for these organizations are able to access the necessary information in their organization.

\subsubsection{Fourth hypothesis: Capability of organizations to provide necessary facilities for maintaining necessary documentation against possible damages}

The second hypothesis surveys whether members of the organizations have good plans to provide necessary facilities for maintaining necessary documentation against possible damages. The ChiSquare is calculated as $66.654>\chi_{4,0.05}^{2}=9.49$. Therefore, we can conclude that the null hypothesis is rejected and there is enough evidence to believe that all organizations have been able to take care of their documentations.

\subsubsection{Fifth hypothesis: On time actions in all organizations}

The fifth hypothesis surveys whether members of studied organizations have executed their duties on time and based on a correct time schedule. The Chi-Square is calculated as $66.684>\chi_{4,0.05}^{2}=9.49$. Therefore, we can conclude that the null hypothesis is rejected and there is enough evidence to believe that employees who work for these organizations are able to execute their jobs based on a good schedule.

\subsubsection{Sixth hypothesis: Good cooperation among members of all organizations}

The last hypothesis is associated whether members of studied organizations have good cooperation to do their duties. The Chi-Square is calculated as $53.786>\chi_{4,0.05}^{2}=9.49$. Therefore, we can conclude that the null hypothesis is rejected and there is enough evidence to believe that employees who work for these organizations cooperate well to accomplish their tasks properly.

\subsection{Prioritizing different criteria influencing emergency logistic preparation distribution management}

We have also used analytical hierarchy process (AHP) (Saaty, 1992) to measure the relative importance of different factors influencing emergency logistic preparation distribution management. A detailed survey among eight experts revealed that there are four factors considered as the most important issues including a good structured database, appropriate operating planning, good definitions on certain duties and their task assignment and supply control. Fig. 1 shows details of our hierarchy. We have asked each member of our decision makers to make a pair-wise comparison of these four attributes and made a geometric mean to find the final average on each pair-wise comparison. 


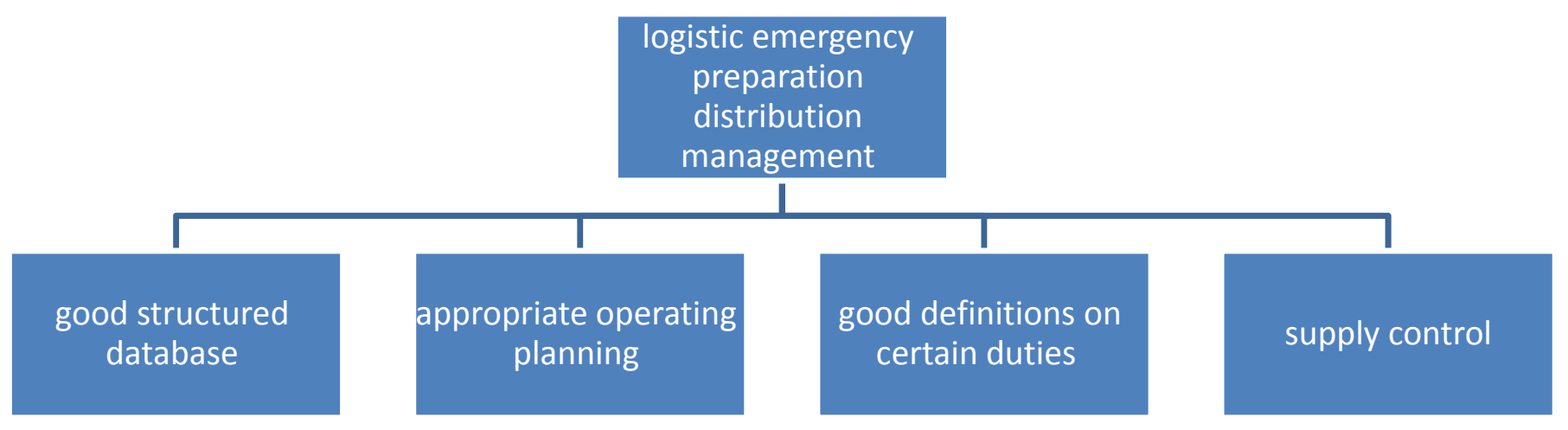

Fig. 1. Important factors influencing emergency logistic preparation distribution management

The implementation of AHP helps us find relative weight of each four measures. In our calculation, having a good database is number one priority with relative weight of 0.51 , followed by appropriate operating planning with relative weight of 0.295 . Supply control comes on the third position with relative weight of 0.134 and finally task assignment comes as the last priority with relative weight of 0.061 .

\section{Conclusion}

In this paper, we have presented an empirical study to find important factors emergency logistic emergency preparation distribution management among people who worked for governorship, hygiene and treatment, Red Crescent, electricity, water and sewage and transportation of central province of Ilam in west part of Iran. The survey distributed a questionnaire among some people and examined six hypotheses. The results of our survey indicate that employees who worked for these organizations maintained high levels of skills; they were able to access what they needed in their organization. In addition, they had the access to the necessary information in their organizations; they could take care of their documentations. Finally, they executed their jobs based on good schedules and accomplished their tasks properly. We have also performed a multi-criteria decision making approach using AHP to prioritize important activities to improve logistic operations. The results indicated that having a good database was number one priority with relative weight of 0.51 , followed by appropriate operating planning with relative weight of 0.295 . Supply control came on the third position with relative weight of 0.134 and finally task assignment came as the last priority with relative weight of 0.061 .

\section{Acknowledgment}

The authors would like to thank the anonymous referees for their comments on earlier version of this work, which has significantly contributed to this paper.

\section{References}

Caunhye, A.M., Nie, X., \& Pokharel, S. (2012). Optimization models in emergency logistics: A literature review. Socio-Economic Planning Sciences, 46(1), 4-13.

Chang, M.S., Tseng, Y.L., \& Chen, J. W. (2007). A scenario planning approach for the flood emergency logistics preparation problem under uncertainty. Transportation Research Part E: Logistics and Transportation Review, 43(6), 737-754.

Gong, B., Chen, X., \& Hu, C. (2012). Fuzzy Entropy Clustering Approach to Evaluate the Reliability of Emergency Logistics System. Energy Procedia, 16(A), 278-283

Hu, Z. H. (2011). A container multimodal transportation scheduling approach based on immune affinity model for emergency relief. Expert Systems with Applications, 38(3), 2632-2639. 
Kaplan, R. S. \& Norton, D. P. (1992). The balanced scorecard - measures that drive performance, Harvard Business Review, 70(1), 71-79.

Kaplan, R.S. \& Norton, D.P. (1996). The balanced scorecard: translating strategy into action, Harvard Business School Press, Boston, MA.

Saaty, T. L. (1992). How to make a decision: the analytic hierarchy process. European Journal of Operational Research, 48, 9-26.

Sheu, J.B. (2010). Dynamic relief-demand management for emergency logistics operations under large-scale disasters. Transportation Research Part E: Logistics and Transportation Review, 46(1), 1-17.

Yuan, Y., \& Wang, D. (2009). Path selection model and algorithm for emergency logistics management. Computers \& Industrial Engineering, 56(3), 1081-1094.

Zhang, J., Dong, M., \& Chen, F.F. (2012). A bottleneck Steiner tree based multi-objective location model and intelligent optimization of emergency logistics systems. Robotics and ComputerIntegrated Manufacturing, In Press. 